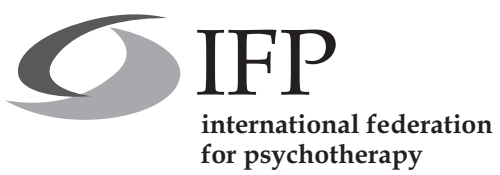

\title{
IFP 2014: 21st World Congress of Psychotherapy - Psychotherapy Contributing to Global Health
}

\author{
May 9-11, 2014, Shanghai, China
}

\section{Invitation}

The International Federation for Psychotherapy (IFP) will hold its 21st IFP World Congress of Psychotherapy on May 9-11, 2014, in Shanghai (China). The conference aims at highlighting the pivotal role of psychotherapy in health care and public mental health.

The IFP 2014 World Congress in Shanghai will offer opportunities to share the world's latest developments in psychotherapy, integrating clinical and research approaches. There will be particular reference to the ongoing political reforms and the opening policy in China (e.g. psychotherapy services in the Chinese mental health system).

Delegates will have an enriching and rewarding experience by attending keynote presentations and plenary lectures, participating in scientific symposia and discussions on selected topics, and engaging in conversations with authors of poster presentations.

Every effort will be made to ensure that the Shanghai Congress contributes meaningfully to improvement in the field of psychotherapy. By attending, you will enjoy learning about a broad spectrum of scientific and clinical approaches and communicating with old and new friends in one of the world's most energetic and innovative cities.

Welcome to Shanghai and the IFP 2014 World Congress!

Franz Caspar, IFP President

Xudong Zhao, Congress President

\section{Important Dates}

- Deadline abstract submission for papers: December 31, 2013

- Deadline abstract submission for posters: January 15, 2014

- Deadline early-bird registration: January 31, 2014

http://www.ifp.name/congresses.htm

\section{Topics}

- Research methodologies

- New developments in psychotherapy

- Psychotherapeutic process

- Epidemiology

- Psychotherapy and clinical medicine

- Quality of life and well-being

- Health promotion and prevention

- Training in psychotherapy

- Continuing education in psychotherapy

- Psychotherapy: West and East

- Psychotherapy and culture

- Philosophical issues

- Ethical and legal issues

- Related topics

\section{Keynote Speakers}

Sartorius, Norman (Switzerland)

Xiao, Zeping (China)

Barber, Jacques (USA)

\section{Plenary Speakers}

Braun, Malena (South America) Caspar, Franz (IFP, Switzerland) Cierpka, Manfred (Germany) Jiang, Guangrong (China)

Mwiti, Gladys (Africa)

Qian, Mingyi (China)

Schnyder, Ulrich (Switzerland)

Tomba, Elena (Italy)

Wang, Ed (USA)

Zhao, Xudong (China)

Zipfel, Stephan (Germany)

\section{KARGER}

E-Mail karger@karger.com www.karger.com/pps
C 2014 S. Karger AG, Basel

0033-3190/14/0832-0130\$39.50/0 